\title{
ARID1A gene silencing reduces the sensitivity of ovarian clear cell carcinoma to cisplatin
}

\author{
CHANGSHUAI LYU, YINGLAN ZHANG，XINGNAN ZHOU and JINGHE LANG
}

\author{
Department of Obstetrics and Gynecology, Peking Union Medical College Hospital, \\ Peking Union Medical College, Chinese Academy of Medical Sciences, Beijing 100730, P.R. China
}

Received October 11, 2015; Accepted October 5, 2016

DOI: $10.3892 /$ etm.2016.3863

\begin{abstract}
In ovarian clear cell carcinoma (OCCC), the mutation rate of the AT-rich interaction domain 1A (ARID1A) gene is $46-57 \%$. However, the effects of ARID1A gene silencing by small interfering RNA (siRNA) on the sensitivity of OCCC to cisplatin have not been investigated. Thus, this study aimed to elucidate the association between ARID1A gene silencing and drug resistance in OCCC. Three pairs of ARID1A gene siRNA fragments (siRNA-1, siRNA-2 and siRNA-3) were designed and transiently transfected into ES2 OCCC cells using RNAi Max reagent. Western blotting results demonstrated that the transfection reduced ARID1A protein expression levels, with the siRNA-3 group having the lowest levels. The $\mathrm{IC}_{50}$ value, determined using a Cell Counting kit- 8 assay, was significantly increased by siRNA-3 transfection compared with that in blank control and negative control groups. The cell survival rate following treatment with $50 \mu \mathrm{M}$ cisplatin for $48 \mathrm{~h}$ was significantly increased in the siRNA-3 group compared with the blank control and negative control groups. Flow cytometric analysis revealed that the apoptosis rate for cisplatin-treated cells was significantly lower in cells with siRNA-3 transfection than in those without, and the apoptosis rate in siRNA-3-transfected cells was lower than that in the negative control group. Western blot analysis showed that the expression level of AKT in cisplatin-treated cells was significantly decreased compared with that in the negative control group, and the AKT expression level in cisplatin-treated cells was significantly higher with siRNA-3 transfection than without. Therefore, the results demonstrated that ARID1A siRNA efficiently decreased ARID1A expression, which reduced cisplatin chemosensitivity and cell apoptosis in ES2 OCCC cells via the regulation of AKT expression.
\end{abstract}

Correspondence to: Professor Jinghe Lang, Department of Obstetrics and Gynecology, Peking Union Medical College Hospital, Peking Union Medical College, Chinese Academy of Medical Sciences, 53 Dongdan North Street, Beijing 100730, P.R. China E-mail: langjinghe@hotmail.com

Key words: ovarian clear cell carcinoma, RNA, small interfering, ARID1 A gene, AKT gene, cisplatin, drug resistance

\section{Introduction}

Ovarian clear cell carcinoma (OCCC) is a rare type of epithelial ovarian cancer with high degree of malignancy, and its incidence is $5-11 \%$ of ovarian epithelial tumors. OCCC is reported to occur at an earlier age than serous ovarian cancer, with a median age at diagnosis of 55 years compared with 64 years (1). Although low-stage OCCC has a relatively good prognosis, advanced-stage OCCC has a significantly lower overall survival rate $(2,3)$. The treatment of OCCC mainly comprises surgery combined with radiotherapy and chemotherapy in a comprehensive treatment program. However, the resistance to platinum-based traditional chemotherapy is very common in the clinic, so the prognosis is poor (4-7).

Chromatin remodeling, including the synthesis, transcription and repair of DNA, is important in cell nuclear activities. Genetic mutation of the chromatin remodeling complex has been identified as a mechanism of tumor occurrence and development (8). The AT-rich interaction domain 1A (ARID1A) as a non-catalytic subunit of the chromatin remodeling complex, has the ability to combine with DNA or protein. Genetic mutations of ARID1A in various tumors are considered to be associated with the biological behavior, treatment and prognosis of the tumor $(9,10)$. In OCCC, the mutation rate of the ARID1A gene has been found to be $46-57 \%$ (11). However, whether such a high mutation rate is associated with the resistance of OCCC to chemotherapy remains unclear and requires investigation. Therefore, the aim of the present study was to evaluate the sensitivity of the OCCC cell line ES2 to cisplatin following silencing of the ARID1A gene and to investigate the possible mechanism.

\section{Materials and methods}

Reagents and antibodies. Lipofectamine RNAi Max reagent was purchased from Invitrogen (Thermo Fisher Scientific, Inc., Waltham, MA, USA). Anti-ARID1A (ab50878) and anti- $\beta$-actin (ab134032) mouse monoclonal antibodies, and anti-AKT (ab179463) rabbit monoclonal antibodies were purchased from Abcam (Cambridge, UK).

Design and synthesis of small interfering RNA (siRNA) sequences. The three pairs of ARID1A gene siRNA interference fragments (siRNA-1, siRNA-2 and siRNA-3), and one 
pair of sequences unrelated to ARID1A (negative control, NC) were designed and synthesized by Shanghai GenePharma Co., Ltd. (Shanghai, China). The siRNA sequences used were as follows: siRNA-1 forward, 5'-GCCCUGAACAAUAAC CUCATT-3' and reverse, 5'-UGAGGUUAUUGUUCAGGG CTT-3'; siRNA-2 forward, 5'-CCAGUCCAAUGGAUCAGA UTT-3' and reverse, 5'-AUCUGAUCCAUUGGACUGGTT-3'; siRNA-3 forward, 5'-CAGCUUGCCUGAUCUAUCUTT-3' and reverse, 5'-AGAUAGAUCAGGCAAGCUGTT-3'; NC forward, 5'-UUCUCCGAACGUGUCACGUTT-3' and reverse, 5'-ACGUGACACGUUCGGAGAATT-3'.

Cell culture and transfection. A ES2 cell line was obtained from the Institute of Basic Medical Sciences, Chinese Academy of Medical Sciences (Beijing, China) and maintained in McCoy's 5A culture medium (Gibco; Thermo Fisher Scientific, Inc.) supplemented with $10 \%$ fetal bovine serum, $100 \mu \mathrm{g} / \mathrm{ml}$ streptomycin and $100 \mathrm{U} / \mathrm{ml}$ penicillin (Sigma-Aldrich; Merck Millipore, Darmstadt, Germany). Cultured cells were incubated in a humidity chamber (Thermo Fisher Scientific, Inc.) containing $5 \% \mathrm{CO}_{2}$ at $37^{\circ} \mathrm{C}$. For transfection, Lipofectamine RNAi Max was mixed with the aforementioned siRNA, according to the manufacturer's instructions. The solutions were subsequently combined with ES2 cells in 6-well culture plates at a density of $3.0 \times 10^{5}$ cells/well. In the blank control group, cells were treated with the transfection reagent only (Lipofectamine RNAi Max); however, in the normal control group, the cells did not undergo any treatment.

Western blot analysis. Cells were washed twice with PBS and lysed in a buffer containing $50 \mathrm{mM}$ Tris (pH 7.6), $150 \mathrm{mM}$ $\mathrm{NaCl}, 1 \mathrm{mM}$ EDTA, $10 \%$ glycerol and $0.5 \% \mathrm{NP}-40$ and protease inhibitor cocktail (Sigma-Aldrich; Merck Millipore). Then, cells were centrifuged for $15 \mathrm{~min}$ at $4^{\circ} \mathrm{C}$ at $14,000 \mathrm{x}$. Protein concentration was determined using a bicinchoninic acid assay (Beyotime Institute of Biotechnology, Shanghai, China). Protein samples $(50 \mu \mathrm{g})$ were separated using $10 \%$ sodium dodecyl sulfate-polyacrylamide gel electrophoresis and transferred onto nitrocellulose membranes. The membranes were blocked using 5\% skimmed milk powder at room temperature for $1 \mathrm{~h}$. Then, the membranes were incubated with anti-ARID1A (1:500), anti-AKT $(1: 1,000)$ and anti- $\beta$-actin $(1: 5,000)$ primary antibodies at $4^{\circ} \mathrm{C}$ overnight, followed by incubation with a horseradish peroxide-conjugated mouse IgG secondary antibody (ab190475; 1:10,000; Abcam) or rabbit IgG secondary antibody (ab190495; 1:10,000; Abcam) at room temperature for $2 \mathrm{~h}$. Proteins were visualized using an enhanced chemiluminescence kit (GE Healthcare Life Sciences, Piscataway, NJ, USA), and the protein band intensity was quantified via densitometric analysis using Quantity One software (Bio-Rad Laboratories, Inc., Hercules, CA, USA).

Cisplatintreatmentand cell viability assay. Cell inhibition rate and cell viability $\left(\mathrm{IC}_{50}\right)$ values for cisplatin (Sigma-Aldrich; Merck Millipore) were determined using the Cell Counting kit-8 (CCK-8; Beyotime Institute of Biotechnology). Cells at a density of $3.0 \times 10^{3}$ cells/well were plated in $100 \mu \mathrm{l}$ medium/well in 96-well culture plates. Following overnight incubation at $37^{\circ} \mathrm{C}$ and $5 \% \mathrm{CO}_{2}$, cells were transfected with
siRNA in the presence of Lipofectamine RNAi Max. After $24 \mathrm{~h}$ of incubation, cells were exposed to cisplatin at a range of concentrations $(20,40,80,120$ and $160 \mu \mathrm{M})$. Each concentration of drug was added to duplicate wells. Following $48 \mathrm{~h}$ of incubation, $10 \mu \mathrm{l} /$ well CCK- 8 reagent was added directly to the medium and the plates were incubated for $1 \mathrm{~h}$. The absorbance values were read on a SpectraMax M3 microplate reader (Molecular Devices, LLC, Sunnyvale, CA, USA) and converted to percentage cell viability in corresponding matched CCK-8-treated cells, which were designated as $100 \%$ viable. $\mathrm{IC}_{50}$ values (concentration of drug that results in a reduction of the absorbance signal by $50 \%$ compared with the CCK-8-treated control) were obtained from nonlinear regression analysis of concentration-effect curves using SPSS software, version 18.0 (SPSS, Inc., Chicago, IL, USA). The $\mathrm{IC}_{50}$ value in the negative control group was $\sim 52 \mu \mathrm{M}$. Then, $50 \mu \mathrm{M}$ cisplatin was added to the plates after transfection, the cells were incubated for $48 \mathrm{~h}$ and the cell survival rate of each group was calculated.

Flow cytometry assay. ES2 cells ( $3 \times 10^{5} /$ well) were plated in $2 \mathrm{ml} \mathrm{medium/well} \mathrm{in} \mathrm{6-well} \mathrm{culture} \mathrm{plates.} \mathrm{Following} \mathrm{over-}$ night incubation at $37^{\circ} \mathrm{C}$ and $5 \% \mathrm{CO}_{2}$, cells were transfected with NC or siRNA-3 siRNA in the presence of Lipofectamine RNAi Max. Following incubation for $24 \mathrm{~h}, 50 \mu \mathrm{M}$ cisplatin was added to the plates and the cells were incubated for a further $48 \mathrm{~h}$ to establish the cisplatin and siRNA-3 plus cisplatin groups, respectively. The single negative control group and single siRNA-3 group were incubated for a further $48 \mathrm{~h}$ but not treated with cisplatin. The cells of the four groups were then collected and labeled using a fluorescein isothiocyanate (FITC) Annexin V Apoptosis Detection kit (BD Biosciences, Franklin Lakes, NJ, USA). Apoptosis rates were determined by flow cytometry (BD Biosciences) and analyzed with FlowJo 10.0.8 software (FlowJo, LLC, Ashland, OR, USA).

Statistical analysis. Each experiment was performed in triplicate and repeated a minimum of three times, with all data presented as the mean \pm standard deviation. Statistical analyses were performed using SPSS software, version 18.0. Comparisons between groups were conducted using the Student's t-test or analysis of variance, where $\mathrm{P}<0.05$ was considered to indicate a statistically significant difference.

\section{Results}

ARIDIA siRNA downregulates the protein expression levels of ARIDIA. Expression levels of ARID1A were analyzed using western blotting. ES2 cells were transfected with siRNA in the presence of RNAi Max reagent for $6 \mathrm{~h}$ and then cultured in McCoy's 5A medium with $10 \%$ fetal bovine serum for $72 \mathrm{~h}$. The results from the western blot analysis revealed that the protein expression levels of ARID1A in the cells of the siRNA-1, siRNA-2 and siRNA-3 groups were all markedly decreased and the level was the lowest in the siRNA-3 group, as compared with the non-siRNA-transfected cells (Fig. 1). Collectively, the results demonstrated that ARID1A siRNA was able to silence ARID1A expression and siRNA-3 interference was chosen for follow-up experiments. 
Table I. $\mathrm{IC}_{50}$ of cisplatin and survival rates of ES2 ovarian clear cell carcinoma cells.

\begin{tabular}{lcc}
\hline Group & $\mathrm{IC}_{50}(\mu \mathrm{M})$ & Survival rate $^{\mathrm{a}}(\%)$ \\
\hline Negative control & $52.55 \pm 3.62$ & $52.67 \pm 2.30$ \\
Blank control & $52.10 \pm 1.10$ & $51.53 \pm 1.81$ \\
siRNA-3 & $77.22 \pm 5.34^{\mathrm{b}}$ & $67.53 \pm 3.35^{\mathrm{b}}$ \\
\hline
\end{tabular}

Data are presented as mean \pm standard deviation $(\mathrm{n}=3)$. ${ }^{\text {a Survival rate }}$ when exposed to $50 \mu \mathrm{M}$ cisplatin for $48 \mathrm{~h}$. ${ }^{\mathrm{b}} \mathrm{P}<0.05$, siRNA-3 vs. the negative control group. siRNA, small interfering RNA.

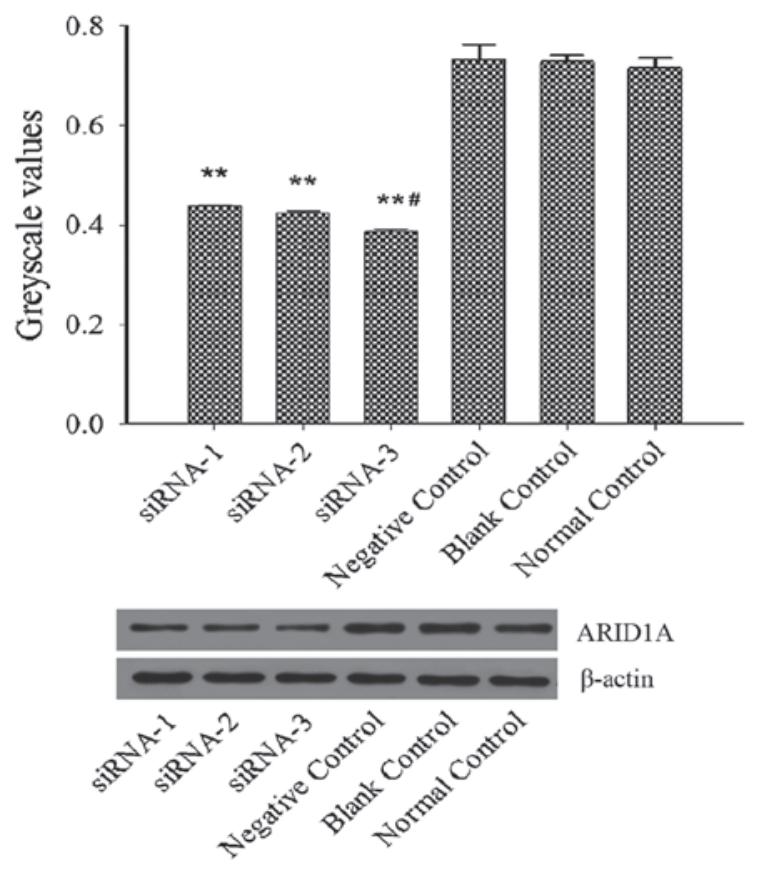

Figure 1. ARID1A siRNA downregulates the protein expression levels of ARID1A. Western blot analysis was used to quantify the expression levels of ARID1A. $\beta$-actin was used as a control for the expression levels. Data are presented as the mean + standard deviation $(\mathrm{n}=3)$. ${ }^{* *} \mathrm{P}<0.01$ vs. the normal control group; ${ }^{*} \mathrm{P}<0.05$ vs. the siRNA-1 or siRNA-2 group. ARID1A, AT-rich interaction domain 1A; siRNA, small interfering RNA.

ARIDIA siRNA reduces cell inhibition rate. To elucidate the effects of ARID1A gene silencing on the cisplatin sensitivity of ES2 cells, cells were exposed to different concentrations of cisplatin. As shown in Fig. 2, at the same concentration of cisplatin, the inhibitory rate of the siRNA-3 group was significantly lower than that of blank control and negative control groups $(\mathrm{P}<0.05)$. The $\mathrm{IC}_{50}$ value in the negative control group was $\sim 52 \mu \mathrm{M}$ (Table I), however, as shown in Table I, the $\mathrm{IC}_{50}$ value in the siRNA-3 group was $\sim 77 \mu \mathrm{M}$ which was significantly higher than that of the negative control and blank control groups $(\mathrm{P}<0.05)$. Then, $50 \mu \mathrm{M}$ cisplatin was added to the 96-well culture plates following transfection and the cell survival rate of each group after $48 \mathrm{~h}$ incubation was calculated. The results showed that the cell survival rate of the siRNA-3 group was higher than that of the other two groups (Table I). These results indicate that ARID1A siRNA decreased the sensitivity of ES2 cells to cisplatin.

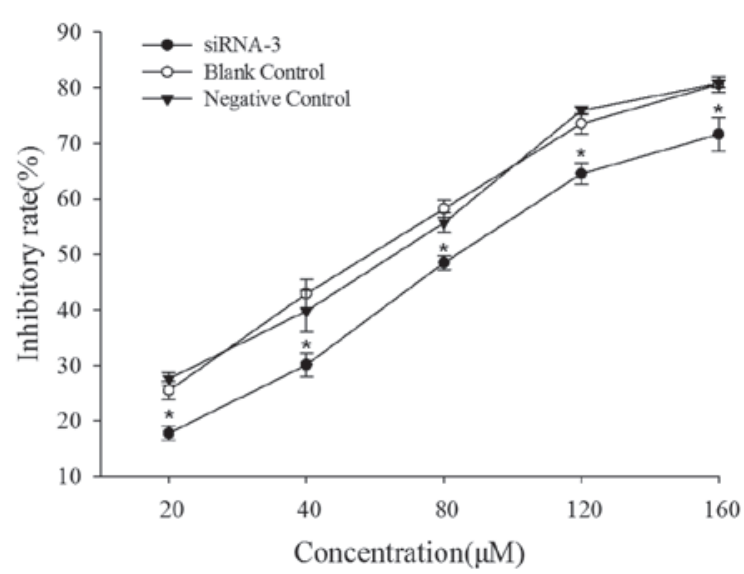

Figure 2. ARID1A siRNA reduces the cisplatin-induced cell inhibition rate. Cell Counting kit- 8 assay was used to determine the inhibitory rates of different concentrations of cisplatin on ES2 cells in each group. Data are presented as the mean \pm standard deviation $(n=3)$. ${ }^{*} \mathrm{P}<0.05$ vs. the blank control or negative control group. ARID1A, AT-rich interaction domain 1A; siRNA, small interfering RNA.

ARIDIA siRNA decreases cell apoptosis. ES2 cells were transfected for $6 \mathrm{~h}$ and then $50 \mu \mathrm{M}$ cisplatin was added to the cells after incubation for $24 \mathrm{~h}$. Apoptotic rates were determined by flow cytometry. The results (Fig. 3) indicate that the apoptotic rate of the siRNA-3 plus cisplatin group (Fig. 3C) was significantly lower than that of the cisplatin group (Fig. 3D). In addition, the apoptotic rate of the siRNA-3 group (Fig. 3B) was lower than that of the negative control group (Fig. 3A). These results demonstrate that that cell apoptotic rate decreased when the ARID1A gene was silenced.

ARIDIA siRNA increases the expression levels of AKT. To elucidate the possible molecular mechanism by which ARID1A siRNA decreased the sensitivity of ES2 cells to cisplatin, the effect of ARID1A gene silencing on the AKT protein level was investigated. The results of western blot analysis (Fig. 4) demonstrated that AKT expression was upregulated in the siRNA-3 group compared with the negative control group. In addition, AKT expression in the cisplatin group was significantly decreased compared with that in the negative control group. Furthermore, AKT expression in the siRNA-3 plus cisplatin group was significantly increased compared with that in the cisplatin group. Thus, ARID1A gene silencing appeared to attenuate the suppression of AKT expression by cisplatin. These results indicate that ARID1A gene silencing decreased the sensitivity of ES2 cells to cisplatin, in part via the upregulation of AKT expression.

\section{Discussion}

OCCC is considered to be a unique clinical and pathological type of ovarian cancer due to its typical histological characteristics; the lesions coexist with ectopic endometrium, are highly resistant to chemotherapy and have a poor prognosis $(2,4,12,13)$. Although little is known about the molecular genetic changes of tumor development, there is a widely accepted tumor hypothesis which considers that OCCC originates from precancerous lesions (such as endometriosis 

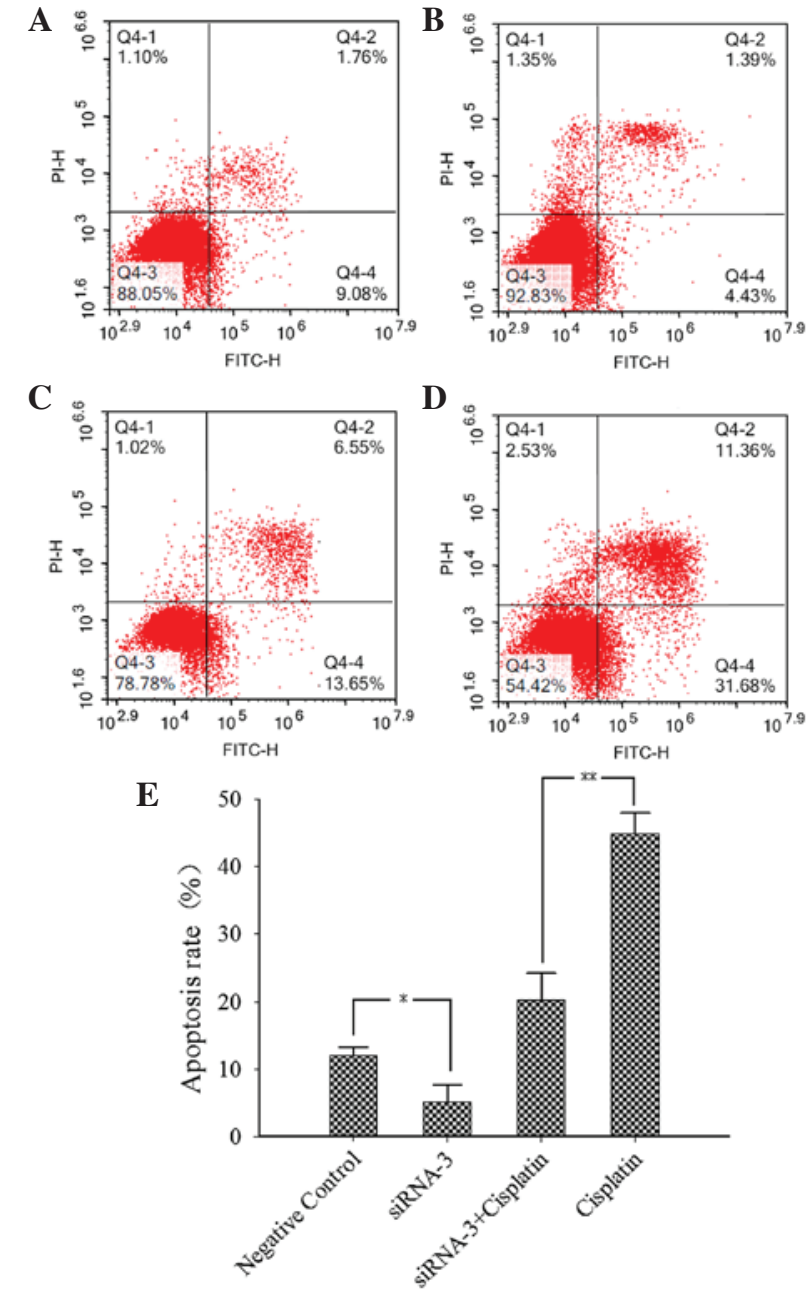

Figure 3. ARID1A siRNA decreases cell apoptosis. Flow cytometry was used to determine the cell apoptosis of the (A) negative control group, (B) siRNA-3 group, (C) siRNA-3 + cisplatin group and (D) cisplatin group. (E) Apoptosis rates in the four groups. Data are presented as the mean + standard deviation $(\mathrm{n}=3) .{ }^{*} \mathrm{P}<0.05 ;{ }^{* *} \mathrm{P}<0.01$. ARID1A, AT-rich interaction domain $1 \mathrm{~A}$; siRNA, small interfering RNA.

and benign clear cell adenofibroma) in the development of the corresponding atypical lesions (such as atypical endometriosis and borderline clear cell adenocarcinoma) $(14,15)$. A previous study found that there was a loss of ARID1A expression in OCCC and adjacent to the ectopic endometrial epithelium, while ARID1A expression was retained in the cystic epithelium distant from the tumor (16). Therefore, ARID1A is considered as a potential tumor suppressor gene, and its expression is closely associated with tumor formation and prognosis (17-19). Patients with advanced OCCC are treated with cytoreductive surgery and chemotherapy with a platinum-based regimen, but the problem of drug resistance has been persistent in the clinic. The high mutation rate of ARID1A in OCCC may be the cause of the resistance to platinum and other chemotherapy drugs. In addition, a study found that after the ARID1A gene was knocked out in Jurkat leukemia cells, there was resistance to FAS-mediated apoptosis (20). The results of the present study also suggest that ARID1A gene mutation may be associated with the drug resistance of tumor cells.

The ES2 cell line is a typical OCCC cell line. In the present study, the sensitivity of ES2 cells to the chemotherapeutic drug

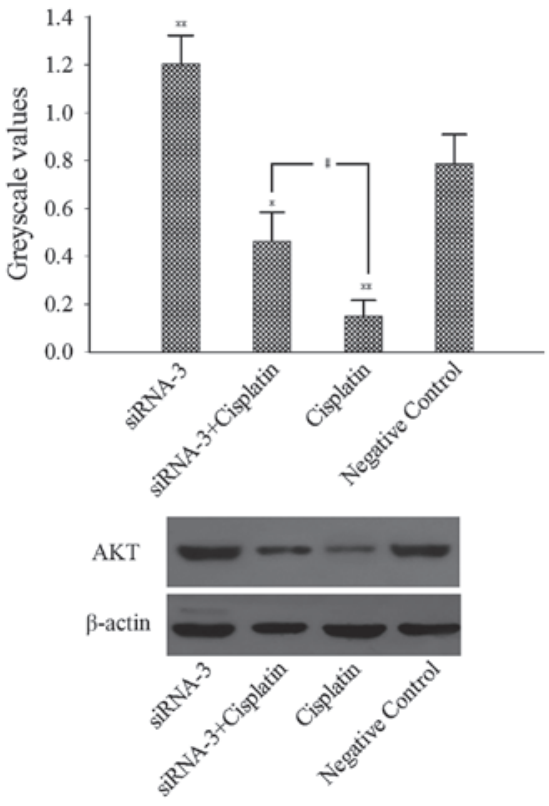

Figure 4. ARID1A siRNA increases the expression levels of AKT. Western blotting was performed to quantify the expression levels of AKT. $\beta$-actin was used as a control for the expression levels. Data are presented as the mean + standard deviation $(n=3) .{ }^{*} \mathrm{P}<0.05$ vs. the negative control group; ${ }^{* * *} \mathrm{P}<0.01$ vs. the negative control group; ${ }^{~} \mathrm{P}<0.05$. ARID1A, AT-rich interaction domain $1 \mathrm{~A}$; siRNA, small interfering RNA.

cisplatin was detected with ARID1A gene silencing, and the results indicated that the $\mathrm{IC}_{50}$ of cisplatin was significantly increased compared with that of the blank control group and negative control group when ARID1A gene expression was reduced by specific siRNA. The cell survival rate of the ARID1A siRNA group was significantly higher compared with that of the negative control group following treatment with the same concentration of cisplatin $(50 \mu \mathrm{M})$. Collectively, these results suggest that ARID1A gene silencing reduced the sensitivity of ES2 cells to cisplatin.

Further investigation into the apoptosis of ES2 cells with ARID1A gene silencing and cisplatin treatment was conducted. The results showed that the cell apoptosis rate of the ARID1A siRNA plus cisplatin group was significantly lower than that of the cisplatin group. In addition, the cell apoptosis rate of the ARID1A siRNA group was decreased compared with that of the negative control group. Therefore, these results indicate that ARID1A gene silencing decreased the apoptosis of ES2 cells and induced resistance to the killing effect of cisplatin on cells to a certain extent.

However, the drug resistance mechanism of tumor cells caused by ARID1A gene mutation is not very clear. Previous studies have reported that a variety of signaling pathways are involved in the phosphatidylinositol 3-kinases (PI3K) family, which regulates cell proliferation, differentiation and apoptosis (21). The signaling pathway constituted by PI3K type IA and its downstream molecular serine/threonine protein kinase B (AKT) is closely associated with the occurrence and development of tumors. Dysregulation of the PI3K-AKT signaling pathway exists in many human tumors, and mutations in certain components change the function of genes and thereby cause the transformation of cells. This pathway is associated with the proliferation, invasion and metastasis of 
tumor cells $(22,23)$. AKT acts on the anti-apoptotic pathway via the phosphorylation of downstream target proteins, and affects the survival of cells through acting on nuclear factor (NF) $-\kappa \mathrm{B}$ and P53. AKT activates inhibitor of NF- $\kappa \mathrm{B}(\mathrm{I} \kappa \mathrm{B})$ kinase by phosphorylation and results in the degradation of $\mathrm{I} \kappa \mathrm{B}$, thereby releasing $\mathrm{NF}-\kappa \mathrm{B}$ from the cytoplasm. The released $\mathrm{NF}-\kappa \mathrm{B}$ carries out nuclear translocation, and then activates target genes to promote survival of the cells $(24,25)$. Previous studies have shown that antisense oligonucleotide to AKT is able to inhibit the growth ability of tumor cells in soft agar, induce apoptosis and increase the sensitivity of tumor cells to chemotherapeutic agents (26). The results of the present study revealed that the AKT expression level in the cisplatin group was lower than that in the negative control group, and the AKT expression in the ARID1A siRNA plus cisplatin group was higher than that in the cisplatin group. Therefore, these results indicate that cisplatin induces cell apoptosis by decreasing AKT expression; however, ARID1A gene silencing caused AKT expression to increase, resulting in resistance to the pro-apoptotic effect of cisplatin to a certain extent, eventually leading to the ES2 cells becoming resistant to cisplatin.

In conclusion, the results of the present study demonstrated that ARID1A gene silencing reduced the sensitivity of ES2 cells to cisplatin via the regulation of AKT expression. These observations further our understanding of the association between ARID1A gene mutation and drug resistance in OCCC and may provide a novel therapeutic target for the treatment of OCCC.

\section{References}

1. Mackay HJ, Brady MF, Oza AM, Reuss A, Pujade-Lauraine E, Swart AM, Siddiqui N, Colombo N, Bookman MA, Pfisterer J, et al: Prognostic relevance of uncommon ovarian histology in women with stage III/IV epithelial ovarian cancer. Int J Gynecol Cancer 20: 945-952, 2010.

2. Chan JK, Teoh D, Hu JM, Shin JY, Osann K and Kapp DS: Do clear cell ovarian carcinomas have poorer prognosis compared to other epithelial cell types? A study of 1411 clear cell ovarian cancers. Gynecol Oncol 109: 370-376, 2008.

3. Takano M, Kikuchi Y, Yaegashi N, Kuzuya K, Ueki M, Tsuda H, Suzuki M, Kigawa J, Takeuchi S, Tsuda H, et al: Clear cell carcinoma of the ovary: A retrospective multicentre experience of 254 patients with complete surgical staging. Br J Cancer 94: 1369-1374, 2006.

4. Sugiyama T, Kamura T, Kigawa J, Terakawa N, Kikuchi Y, Kita T, Suzuki M, Sato I and Taguchi K: Clinical characteristics of clear cell carcinoma of the ovary: A distinct histologic type with poor prognosis and resistance to platinum-based chemotherapy. Cancer 88: 2584-2589, 2000

5. Takano M, Tsuda H and Sugiyama T: Clear cell carcinoma of the ovary: Is there a role of histology-specific treatment? J Exp Clin Cancer Res 31: 53, 2012.

6. Winter WE III, Maxwell GL, Tian C, Carlson JW, Ozols RF, Rose PG, Markman M, Armstrong DK, Muggia F and McGuire WP; Gynecologic Oncology Group Study: Prognostic factors for stage III epithelial ovarian cancer: A Gynecologic Oncology Group Study. J Clin Oncol 25: 3621-3627, 2007.

7. Ho CM, Huang YJ, Chen TC, Huang SH, Liu FS, Chang Chien CC Yu MH, Mao TL, Wang TY and Hsieh CY: Pure-type clear cell carcinoma of the ovary as a distinct histological type and improved survival in patients treated with paclitaxel-platinum-based chemotherapy in pure-type advanced disease. Gynecol Oncol 94: 197-203, 2004.

8. Guan B, Wang TL and Shih IeM: ARID1A, a factor that promotes formation of SWI/SNF-mediated chromatin remodeling, is a tumor suppressor in gynecologic cancers. Cancer Res 71: 6718-6727, 2011.
9. Lichner Z, Scorilas A, White NM, Girgis AH, Rotstein L, Wiegand KC, Latif A, Chow C, Huntsman D and Yousef GM: The chromatin remodeling gene ARID1A is a new prognostic marker in clear cell renal cell carcinoma. Am J Pathol 182: 1163-1170, 2013.

10. Ozawa Y, Nakamura Y, Fujishima F, Felizola SJ, Takeda K, Okamoto H, Ito K, Ishida H, Konno T, Kamei T, et al: Decreased expression of ARID1A contributes to infiltrative growth of esophageal squamous cell carcinoma. Tohoku J Exp Med 235: 185-191, 2015.

11. Wiegand KC, Shah SP, Al-Agha OM, Zhao Y, Tse K, Zeng T, Senz J, McConechy MK, Anglesio MS, Kalloger SE, et al: ARID1A mutations in endometriosis-associated ovarian carcinomas. N Engl J Med 363: 1532-1543, 2010.

12. Mizuno M, Kikkawa F, Shibata K, Kajiyama H, Ino K, Kawai M, Nagasaka T and Nomura S: Long-term follow-up and prognostic factor analysis in clear cell adenocarcinoma of the ovary. J Surg Oncol 94: 138-143, 2006.

13. Itamochi H, Kigawa J and Terakawa N: Mechanisms of chemoresistance and poor prognosis in ovarian clear cell carcinoma. Cancer Sci 99: 653-658, 2008.

14. Kurman RJ and Shih IeM: The origin and pathogenesis of epithelial ovarian cancer: A proposed unifying theory. Am J Surg Pathol 34: 433-443, 2010.

15. Veras E, Mao TL, Ayhan A, Ueda S, Lai H, Hayran M, Shih IeM and Kurman RJ: Cystic and adenofibromatous clear cell carcinomas of the ovary: Distinctive tumors that differ in their pathogenesis and behavior: A clinicopathologic analysis of 122 cases. Am J Surg Pathol 33: 844-853, 2009.

16. Ayhan A, Mao TL, Seckin T, Wu CH, Guan B, Ogawa H, Futagami M, Mizukami H, Yokoyama Y, Kurman RJ and Shih IeM: Loss of ARID1A expression is an early molecular event in tumor progression from ovarian endometriotic cyst to clear cell and endometrioid carcinoma. Int J Gynecol Cancer 22: 1310-1315, 2012.

17. Mao TL, Ardighieri L, Ayhan A, Kuo KT, Wu CH, Wang TL and Shih IeM: Loss of ARID1A expression correlates with stages of tumor progression in uterine endometrioid carcinoma. Am J Surg Pathol 37: 1342-1348, 2013.

18. Itamochi H, Oumi N, Oishi T, Shoji T, Fujiwara H, Sugiyama T, Suzuki M, Kigawa J and Harada T: Loss of ARID1A expression is associated with poor prognosis in patients with stage I/II clear cell carcinoma of the ovary. Int J Clin Oncol 20: 967-973, 2015.

19. Kim MJ, Gu MJ, Chang HK and Yu E: Loss of ARID1A expression is associated with poor prognosis in small intestinal carcinoma. Histopathology 66: 508-516, 2015.

20. Luo B, Cheung HW, Subramanian A, Sharifnia T, Okamoto M, Yang X, Hinkle G, Boehm JS, Beroukhim R, Weir BA, et al: Highly parallel identification of essential genes in cancer cells. Proc Natl Acad Sci USA 105: 20380-20385, 2008.

21. Katso R, Okkenhaug K, Ahmadi K, White S, Timms J and Waterfield MD: Cellular function of phosphoinositide 3-kinases: Implications for development, homeostasis, and cancer. Annu Rev Cell Dev Biol 17: 615-675, 2001.

22. Bosse T, ter Haar NT, Seeber LM, v Diest PJ, Hes FJ, Vasen HF, Nout RA, Creutzberg CL, Morreau H and Smit VT: Loss of ARID1A expression and its relationship with PI3K-Akt pathway alterations, TP53 and microsatellite instability in endometrial cancer. Mod Pathol 26: 1525-1535, 2013.

23. Ptak A, Hoffmann M, Gruca I and Barć J: Bisphenol A induce ovarian cancer cell migration via the MAPK and PI3K/Akt signalling pathways. Toxicol Lett 229: 357-365, 2014.

24. Jeong SJ, Pise-Masison CA, Radonovich MF, Park HU and Brady JN: Activated AKT regulates NF-kappaB activation, p53 inhibition and cell survival in HTLV-1-transformed cells. Oncogene 24: 6719-6728, 2005.

25. Lin P, Yi Y, Lu M, Wang M, Yang Y, Lu Y, Song S, Zheng Z, Deng $X$ and Zhang L: Heat shock protein 90 inhibitor mycoepoxydiene modulates kinase signaling in cervical cancer cells and inhibits in-vivo tumor growth. Anticancer Drugs 26: 25-34, 2015.

26. Chang F, Lee JT, Navolanic PM, Steelman LS, Shelton JG, Blalock WL, Franklin RA and McCubrey JA: Involvement of PI3K/Akt pathway in cell cycle progression, apoptosis, and neoplastic transformation: A target for cancer chemotherapy. Leukemia 17: 590-603, 2003. 